\title{
Article
}

\section{Field Work Reflections: Journeys in Knowing and Not-Knowing}

\author{
Roy, Alastair Neil
}

Available at http://clok.uclan.ac.uk/15006/

Roy, Alastair Neil ORCID: 0000-0002-4807-7352 (2016) Field Work Reflections: Journeys in Knowing and Not-Knowing. Qualitative Social Work . pp. 1-14. ISSN $1473-3250$

It is advisable to refer to the publisher's version if you intend to cite from the work. http://dx.doi.org/10.1177/1473325016657868

For more information about UCLan's research in this area go to

http://www.uclan.ac.uk/researchgroups/ and search for < name of research Group $>$.

For information about Research generally at UCLan please go to http://www.uclan.ac.uk/research/

All outputs in CLoK are protected by Intellectual Property Rights law, including Copyright law. Copyright, IPR and Moral Rights for the works on this site are retained by the individual authors and/or other copyright owners. Terms and conditions for use of this material are defined in the policies page.

\section{CLoK}

Central Lancashire online Knowledge www.clok.uclan.ac.uk

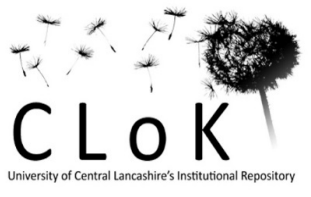


Field Work Reflections: journeys in knowing and not-knowing

\title{
Alastair Roy
}

\begin{abstract}
In this paper I retrace my interest in narrative forms of inquiry. I begin by revisiting a series of research projects that I conducted early in my career, describing some of my own dissatisfactions with the methods I used at the time. I move on to a detailed re-examination of my first piece of narrative research, completed during my PhD. In that project I used a narrative pointed psychosocial method in an attempt to develop new knowledge in the field of drugs, 'race' and ethnicity. In the final section I consider what I have learned from this approach in terms of knowing and not-knowing and how I have used this experience to explore different approaches to narrative inquiry. I finish by drawing out some lessons I have learned from these different studies, which I hope might be of relevance to other social work researchers.
\end{abstract}

\section{Introduction}

If knowledge is ... made, then making has to be understood in the sense implied when we say of people that they 'make their way' in the world. It is not a construction, governed by cognitive mechanisms of one sort or another, but an improvisatory movement - of 'going along' ... that is openended and knows no final destination (Ingold, 2010: S122).

For much of the last 15 years I have been conducting research in the field of substance use and misuse. This work began in 2000 when I started work on a five-year quantitative study of the substance use attitudes and behaviours of children in their final year of compulsory schooling in Manchester, England. These data were gathered by self-completion questionnaire, which happened in lesson time in schools, with the questionnaires administered by researchers and teachers not present. Completing the questionnaires took about 20 minutes, which left about 20 minutes for discussions with the pupils. I can remember being interested in the ways in which the students introduced and talked about 
drugs and drug issues with me in these in-school discussions. The quantitative data produced some interesting findings, providing an analysis of the extent to which certain views were held across a large population of young people (sample $n=4059$ ). In a subsequent paper we argued that the data supported a picture of the normalisation of certain forms of substance use in the sample (Roy, Wibberley and Lamb, 2005). However, I was disappointed that the rich discussions held with pupils in-class could not be included. Hence, taking part in this project framed my understanding of the strengths and limitations of longitudinal questionnaire-based designs set within an objectivist epistemology.

In 2003 I began work for a centre which specialised in research around the drug service needs and issues of Black and Minority ethnic communities in England. The centre conducted a lot of projects commissioned by government departments and I was attracted to the role both by the subject matter and the preference in the unit for qualitative methods. However, those who commissioned drug research in the UK at the time were strongly disposed to rational and objectivist epistemologies (Macgregor, 2011). Perhaps as a result many of our projects employed qualitative methods imbued with the ontological imprint of positivist social science, as we engaged in forms of epistemological fence sitting. In one Home Office funded project about the accessibility of prison drug services for different ethnic groups (Fountain et al. 2007; Roy et a. 2007) we conducted more than 300 semi-structured interviews with people from groups pre-defined by ethnic characteristics (e.g. South Asian, Black African). Interviewee responses were analysed thematically, with responses under certain themes grouped together and often set out as proportions of the sample that said $\mathrm{x}$ or $\mathrm{y}$ which were supported by a series of - decontextualized - quotes, such as the ones in the box below.

For some, contact with prison drug services represented their first contact with any drug service, and many of those who developed a positive relationship with their prison drug worker were concerned about starting again with a new worker on release. Many of the prisoners interviewed for this study agreed:

I want to continue getting help from the drug services, but may not be able to. I get on with my drug worker here. If I could get referred to someone and meet them before and could get to know them, maybe I would see them then [on release]. (Black African, ic)

I am going in it [drug service on release] blind. I would prefer to meet them first inside. (White British, ic)

Fountain et al. (2007: 70) 
In the excerpt above we have an argument made by the researchers, supported by two quotes. Below the quotes, two details of the people who gave them are given. First, we get a description of their ethnicity and second, the code 'ic' is given to indicate that this person was had indicated that they were contact with prison drug services. Duneier identifies some important limitations in these ways of presenting data, suggesting ...

“If you are going to get at the humanity of people, you can't just have a bunch of disembodied thoughts that come out of subjects' mouths in interviews without ever developing characters and trying to show people as full human beings" (Duneier and Back, 2006: 554).

Furthermore, such presentations fail to give any sense of the interview setting or interaction. Scheff (1997) develops the idea of the 'cultural convention of common sense', which usefully characterises the epistemological assumptions behind these sorts of qualitative studies. What Scheff directs our attention towards, in developing this idea, is that in many qualitative interviews, people assume a research relationship in which 'one can ask questions and get straight answers' and imagine a research subject that 'knows its own mind and can communicate this largely in an autonomous fashion' (Hollway, 2001: 13).

As I prepared for my PhD study I began to look again at the field notes from the Home Office study and I listened again to some of the interview recordings. As I did so, I remembered that we had been under pressure from the Home Office to generate a large sample, which they felt would strengthen the evidence. And, that we were also sometimes put under pressure by Prison Officers to complete interviews quickly in order to comply with institutional time frames such as the end of shifts or meal times. I listened uncomfortably to some of the recordings, realising that I had sometimes found it difficult to create the right sort of attention within these interviews. Despite efforts to be sensitive, I also noted examples in some interviews in which I had cut short certain responses.

As I began to develop the ideas for my PhD I was keen to find a way of conducting research that would allow respondents to talk about the meaning of issues such as drug use, culture and identity in ways which related to their own lives, experiences and situations and I began to read about narrative approaches to research. Chase (1995: 2) suggests that 'attending to another's story in the interview context requires an altered conception of what interviews are and how we should conduct them.' In providing people with the 
space to tell a story, we provide them with the responsibility for choosing the beginning, the middle and the end, and for making the relevance of the story clear. However, in psychosocial approaches, stories are not assumed to 'tell it like it is' (Hollway and Jefferson, 2000/2012) (to offer a transparent account) but, through interpretive analysis, are seen to offer a means to develop understandings about participants as situated subjects.

I was particularly interested in adopting an approach which would allow me to work in a detailed way with individual cases. This was in part born of the frustrations I describe earlier about the Home Office research, but also because I recognised that the analysis of single cases offered the distinctive possibility to explore the ways in which humans choose, think and act in their own lives (Rustin, 1991). This seemed particularly important in trying to understand how and why someone might develop drug problems as well as understanding their attempts to access treatment and support. In 2010 I conducted research that examined the life narratives of a number of people who were accessing treatment and support for drug issues (Roy, $2012 \mathrm{a}$ and b). This project provided a methodological freedom that had not been available in much of my previous commissioned research. The project was supported by Manchester Drug Service, which allowed me to approach clients through five of its service sites.

In what follows I begin with a brief description of the methodology. Here I describe how the criticisms I level at my earlier research were translated into a new set of epistemological and methodological commitments. I then work with a single case from the research, that of Bobby, setting out an abbreviated version of the story he tells about his own life. This is a case that I have written about before (Roy, 2012b), hence some elements of the methodology and the case are repeated. However, in the discussion that follows I use the case to re-examine the epistemology and methodology and to consider what might be learned from revisiting this approach.

\section{Methodology}

In the study I chose a narrative method in an attempt to provide participants with the opportunity to tell their own story and me the opportunity to attend to this (Wengraf, 2001). I wanted a method that could be respectful to research subjects as individuals and which would allow me to think carefully about individual cases before moving to consider any wider generalisation. I chose a method-The Biographical Narrative Interpretive Method (BNIM)-with a clear structure and form as well as its own training programme which I completed before I began the work. 
BNIM sees individuals as thinking acting subjects who craft and shape their own meaning as they tell their stories. However, it assumes that this telling is mostly not intentional, but mainly a result of habitual personal characteristics and approaches. For Wengraf (2001), the participant in the BNIM interview is a narrative self with a personal 'gestalt' of sedimented experience that is part of a personal system of relevance (Gunatatnam, 2009). The method employs a minimalist form of interviewing structured deliberately to allow this personal gestalt to reveal itself. However, it recognises that many factors can influence the story that is told in the interview as well as the subsequent analysis and presentation of it.

The BNIM interview has two sub-sessions. The first starts with a single opening question, along the lines of 'Please tell me the story of your life.' This initial question is designed to encourage the interviewee to respond and encourages the interviewer to attend to that response without interruption. The role of the interviewer in this first sub-session is to be a sort of silent midwife to narrative. Hence she is directed to encourage responses through non-verbal cues but told not to offer any further verbal direction in this section of the interview. Gunaratnam (2013) uses the image of hitting the minimise key on a computer keyboard to convey how the BNIM approach affects the role of the researcher. In my own practice I have found that this takes time to get used to this and I found it difficult to live with the inevitable silences when I started working in this way.

In sub-session two, the interviewer selects a number of points made by the interviewee in the first sub-session to ask further questions about; these always include the first and last points made. The points are taken in the order they were given in the interview, hence respecting the structure of the story told by the interviewee. The interviewer uses the phrasing of the interviewee, seeking further narrative responses. In particular, the interviewee is encouraged to push for Personal Incident Narratives (PINS); another way of describing these might be first hand accounts of specific situations or events. So the interviewer is encouraged to ask - open narrative seeking ('You were describing when your dad left, do you remember how that all happened?') type questions, rather than questions that ask for generalisation or opinion ('What did you think when your dad left?'). The reasons given for avoiding why questions is partly because responses to these sorts of questions often fail to get close to experience, but also because some people might find talking about their views and emotions threatening which might lead to forms of censure, in which accounts tend towards what is seen - in this interview context - as socially acceptable (Gunaratnam 2013). The presumption is that people's current opinions can get in the way of providing an account of what actually happened at the time. 
BNIM has an interpretation process predicated on the use of diverse panels. These should be done by a group of people who are 'unlike' the interviewer and 'both like and unlike' the interviewee (Wengraf, 2001: 258). The idea is that the panels bring a wider life experience and set of viewpoints to bear on both the data and the role of the researcher. Together the panels work - future-blind through the interview data - which is revealed chunk by chunk - attempting to relive what is told one moment or event at a time. The panel members make hypotheses about what will happen next and as they move through the analysis these are tested against subsequent chunks of data.

The panels also explore the research relationship. In psychosocial research this is viewed as important because the interviewee and the lone researcher are both viewed as only partially able to understand their own pre-dispositions and, in the case of the researcher, this is argued to affect the interpretation of texts (Froggett and Wengraf 2004). This perspective views the interaction between researcher and researched as influenced by interpersonal phenomena which include psychodynamic transactions that affect both the content of a narrative and the way it is told (Buckner, 2006).

In what follows I begin by providing a brief discussion of one of the cases from this study. This develops a psychosocial analysis of interviews with Bobby (not his real name), a mixed race man in his 50s who had been in recovery from heroin and methadone addiction for four years at the time of the interviews. I begin by presenting a short description of the interview context and an abbreviated version of the story Bobby tells of his own life. I then consider a couple of the ideas that emerged through the panel analysis as part of revisiting the approach.

\section{A case study from the research}

\section{Describing the interview scene}

The day I meet Bobby, it's at a Manchester Drug Service (MDS) site near Strangeways Prison in Manchester, England. The prison tower casts a huge presence over the surrounding area and as I walk up from the tram stop I think about the prisoners on the roof during the riots in 1990 just after I moved to the city. The MDS building is fairly typical of many drug services I have visited, it is nondescript on the outside and people are standing around the doorway smoking when I arrive. I wonder if any of them is Bobby. I have been given the use of a meeting room to do the interviews, it has old office furniture in it and is warm and clean. I sit down and look at the plastic coated oversized and brightly coloured prints of flower heads on the walls; I wonder what they are supposed to 
convey? I start to get my things ready and after about ten minutes Bobby pops his head around the door. He's tall, average build, I guess he's in his 50s. He speaks softly in a Mancunian accent. Bobby asks if he can make himself a brew, I hear him mention the interview to someone and a few minutes later he returns, sits down and we start.

\section{A brief summary of the story Bobby tells about his own life}

Bobby was born in the late 1950s in a district of Manchester called Burnage. He describes his father as Black African and his mother as white British. He says his mother was 'hands on ... affectionate' and 'a lovely woman' and his father was 'like many of those types of guys, he was African, and he used the whip' and 'there wasn't too much emotion or feeling, that kind of thing that a child needs'. Bobby describes his parents' relationship as 'complex', and at different points in the interview he refers to the upsetting and difficult ways that they both spoke to him about 'race' and difference, for example:

And she said, to me, and to my brother, don't turn out like a typical black man.

To-me dad, I even got it from him, you know that half-breed, no good, I don't know where that come from, ...

Bobby had one brother who was ten years older. He says he was the only nonwhite child in his primary school saying he was 'happy there' and 'made friends easily'. At the age of six his mother contracted cancer and went into hospital. Bobby was placed in foster care 'with a white family' which he describes as 'difficult'. His older brother stayed at home with his father. His mother died when he was eight and he returned to the family home at this time. After the death of his mother, who he describes as 'the only person who showed me any physical affection', Bobby describes how he begins giving himself nose bleeds in school. This starts by virtue of a genuine accident but becomes a recurrent habit because of the response it elicits from female teachers.

"The smell and care and touch, just to know that someone could see me (2) and care, and touch, cause I kind of felt (1) invisible ...." [numbers in brackets indicate pauses timed in seconds.]

Bobby was one of five non-white pupils in a large and subsequently notorious secondary school ${ }^{1}$. He left school at 15 for an apprenticeship. After 18 months it

\footnotetext{
${ }^{1}$ Burnage High School, where in 1986 a South Asian pupil was murdered by a white pupil. The case led to the McDonald Inquiry which investigated racial violence in Manchester schools.
} 
was terminated 'due to poor time keeping'. As a result his father 'kicked' him 'out' of the family home and Bobby moved to another place in the city 'initially sleeping on friends' sofas'. He began offending with other young men and served sentences in youth offending institutions and the prison system. He describes being subject to 'severe racism' from white prison officers, saying 'racism was so pervasive and unquestioned that officers wore National Front badges on their uniforms'.

At 19 he had his first child. The mother subsequently moved away with another man when Bobby was in prison. He didn't see his daughter until she was an adult. He stopped offending in his early twenties and began another apprenticeship and worked 'on and off' as a tradesman until his late twenties. He began another long-term relationship with a young woman in his early twenties (she was 18). They had three children together. He 'looked after the children' with the mother in their early life and talked warmly about everyday things like walking them to school. However, he separated from her when he was in his late 20s ('due to my addiction') and she 'started another relationship and moved away' to a different part of the country. After the separation he had no contact with the children before they were adults. He has some contact with two of them now.

Bobby describes himself as a 'talented football player'. He played for the school team and other teams throughout his childhood. Between the ages of 18 and 24 he 'played in the Manchester leagues'. He is relay animated when he discusses football. I'm a big football fan too and he appreciates my interest. In discussing football, Bobby makes reference to a sense of his own 'agency' and he explicitly contrasts his experience of himself on the football field to his experience in other areas of his life, describing a sense of 'freedom'. It's one of the few places in which other people seem to recognize his ability. However, this recognition is double edged and he also refers to 'monkey chants', 'name calling', the racialised projections of his own teammates in accounting for his 'speed and ability', and the structural racism in league football. He was eventually offered a trial by a professional team at the age of 24 but was not offered a professional contract. Shortly after this he got seriously injured and had to stop playing football altogether.

At 25 Bobby first used heroin with two close friends who were already regular users. The following quote is part of how he describes the day he went to find his friends who were using heroin:

I went to see a friend with a view to finding out (1) and there they were with an ounce of heroin on the floor, two of them like stick insects, ashen faced, mixed-race guys [laughs whilst saying last seven words] grey (2) 
and curiosity got the better of me and 'what's this thing about?' Obviously I'd been carrying on with these other things inside me. The strange thing is, I felt I'd lost all my friends (1) and I wanted in, (2) I wanted to see what was going on ... so all me struggles went away and (2) ooohhh [exhales loudly while speaking] (1) and I didn't immediately take it ... [sections in bold indicate emphasis in expression.]

Seemingly reliving the moment, he laughs out loud at the idea of these 'stick insect, ashen faced, mixed race guys' using heroin. However, within 12 months he was a daily dependent user. He used for more than 20 years, eventually beginning methadone maintenance in his late 40s. He funded his use through paid employment, crime and drug supply. At the point of the interview Bobby had been free from heroin for six years and free from methadone for two years and was using Narcotics Anonymous for support. He described the physical damage that he was carrying as a result of his addiction and the difficulties of coming to terms with the fact that he might never work again. He also described his struggles to rebuild relationships with his children as adults and the difficult sense of guilt and loss attached to the years in which they had not been in contact and in which he had not been a father.

\section{Field work reflections}

\section{The past}

Re-reading the account of the interview with Bobby more than five years on from when it took place it's striking how much I recall about the day, the place, his arrival, his gentle demeanour, the soft sadness of his voice, the way in which he told his story and how certain things were expressed, emphasised or concealed. I can also recall, rather uncomfortably, times in the interviews in which communication became more constrained and difficult and I have written about this in detail before (Roy, 2012b).

In comparison, when I try and recall some of the people from the Home Office study-I referred to earlier-it's generally much harder to bring them to mind. In a way this is quite an obvious reflection, not least because these BNIM interviews were much longer than the others and because I worked with them in so much depth in producing the work for my PhD. But it's possible that these clear recollections have more to do with the forms of attention that I brought into this research. Questions of attention are at the heart of 'how we come to know' in qualitative inquiry. Also, questions about how we come to know, imply certain methodologies and methods, imposing a further set of questions about how our research encounters might be staged and to what effect (Back, 2008). 
Earlier in the paper I set out my own frustrations with the approach developed in the Home Office study (Fountain et al. 2007). I describe this in terms of epistemological fence sitting in which we developed qualitative methods imbued with an objectivist epistemological frame. The result was an interview approach characterised by the face-to-face mining of other people's experience, in which it was hard to sustain an attention on individual lives and concerns. Instead, our attention in interviews was directed to eliciting talk about specific issues and subjects, such as the barriers to accessing drug treatment services. To return to Gunaratnam's image of the computer keyboard, this approach is equivalent to pressing the maximise key on a computer, because the encounters were clearly led by the researcher in the service of predefined aims and objectives. In the analysis, faced with responses from over 300 people, our interest was quickly drawn to the patterns of response to certain questions across the sample. This was exemplified in the report in which we identified themes across the data and presented these in terms of proportions of the sample who said $\mathrm{x}$ or $\mathrm{y}$. It is also evidenced by the way in which a series of short quotes-ones which erased from view the lives, situations and contexts of those who offered them-were used to emphasise certain themes we developed in the report. The anthropologist Paul Nadasdy (1999, cited in Ingold 2011) uses the terms 'distillation' and 'compartmentalisation' to describe the conversion of data in this way. Distillation being the process of breaking the link between data and its narrative context and compartmentalisation being a subsequent process of classifying these data into categories. These terms are helpful in describing the ways in which such processes are epistemologically out of kilter with qualitative inquiry.

In the BNIM study I adopted a new approach in an attempt to address these issues. By offering my participants the opportunity to tell their own life story, I provided them with the broadest possible canvas, allowing them to choose where the story should begin and end and what to include. Bobby chose to tell a story which focused in great detail on his early life and, at the time, I can remember wondering about the relevance of some of this. It's easy to see that if I had directed the encounter that much of this material might never have appeared. The image of the minimise key perfectly captures the researchers role within the BNIM interview, in which the objective is to create a space in which we quietly attend to what participants choose to tell us. Gunaratnam (2013) develops this discussion, suggesting...

One of the most challenging and vital skills for a narrative interviewer is to 'go with the flow', allowing the gestalt to emerge in its own way without interruptions - no matter how incoherent or 'off the point' certain accounts can feel. 
Narrative research is driven by a concern to give detailed and respectful consideration to individuals as subjects whilst also attempting to extend knowledge by considering the applicability of one person's experience and concerns to wider social patterns and issues. The narrative approach I adopted offered Bobby the chance to tell his own story and to make its relevance clear in his own way. The story about Bobby's first use of heroin appeared late in the second interview, and actually emerged from him talking about the end of his football career. In the interview, I gently encouraged Bobby to recall the day this happened. He didn't do this immediately. He started by talking generally about things that were happening at the time and then eventually described the actual event as a first person story. Bobby was able to recall and retell the story in terms of actual events on that day.

Detailed panel analysis supported a careful and chronological exploration of this material from the interview. It was noted during this work that on three occasions that Bobby mentioned football that he mentioned drugs in the same sentence and that this link in the story was accompanied by a chronological link in which drugs almost immediately followed football in his life. In the interview Bobby talks about 'these other things inside me' and how 'he wanted in'. Hence, through a narrative approach I was able to look at Bobby's life in detail, helping to explore the complex web of psychic, social and historical processes which influenced his view of drug use, his decision to use heroin, his career as a heroin user and his eventual route away from it (Wengraf, 2001, p. 315). Hence, whilst there is something highly individual and idiosyncratic about Bobby's story, it also helped shed light on more general elements of the lives of mixed-race drug users at the time.

\section{The present}

When I undertook my first narrative study I was drawn towards BNIM for several reasons. The minimal interview approach provided a distinct and valued contrast to my previous practice. I knew several colleagues who had used BNIM and knew that it had been used for numerous PhD studies in the past. BNIM also came with it's own training programme and Tom Wengraf, who delivered the training, provided generous additional support through my early interviews. All these factors gave important elements of reassurance for me in trying out a new approach.

In 2013 I was working on a research project with Jenny Hughes about an organisation-The Men's Room-working with young male sex workers in Manchester (Hughes, Roy and Manley, 2014; Roy et al. 2015). During an 
extended period of ethnography we realised that finding out more about the young men's everyday lives outside the service would help us to understand their support needs better. I was keen to develop a narrative approach. However, I was fearful that trying to conduct face-to-face interviews with the young menwhether semi-structured or narrative pointed-would initiate highly defensive performances. I knew from my own experience of working with them how many of the young men struggled with face-to-face interactions. I also thought these sorts of interview might have unfortunate associations with interviews they had experienced with the police, probation officers and social workers.

One night whilst I was at The Men's Room one of the young men said to me "if you really want to find out how young men survive in the city, you need to go out and talk to men in the city". This seemed to be an important provocation from the men we were working with to get mobile. In a reflection on the research that led to the book Sidewalk, Mitchell Duneier refers to a similar moment in which one of the street vendors he was researching said to him "If you really want to understand this, why don't you become a street vendor". Conversations with participants which include phrases such as this ("if you really want to find out") are precious moments, because they indicate an interest in and critical engagement with the research process and the question of how we might come to know. The young man in my own research instinctively knew what Bordieu (2000 cited in 0'Neill 2014) taught his students, that the staging of interviews (including the spaces and places in which they happen as well as the interview process), significantly influences the ways in which power is felt and hence the modes of communication and the story that can be told.

Through the productive engagement of the young men we were able to initiate an interview approach in which we invited young men to lead us on a city centre tour of sites that they associated with their own survival. We walked and talked through the city with the young men and on arrival at each stop on the tour, we invited them to take a photograph and if they wanted, to tell us a story related to the site. We completed seven walking tour interviews. Each provides a view of the challenges of survival in the pasts, presents and futures of the young man who led it (Hughes, Roy and Manley, 2014). Using this approach allowed me to maintain the epistemological commitments of my earlier narrative research. It created a space in which the young men could lead the encounters and in which we could walk side by side, attending to what unfolded. Additionally, walking and talking created a rhythmic relaxation which seemed to allow for more open forms of dialogue (Anderson, 2004). Finally, the side-by-side encounter created an interview form in which the young men found it possible to engage in moments of intense sharing, whilst also allowing moments when we could walk quietly together without any need for a response. 
The methodology developed in the Men's Room project built on a recognition that the methods we use create conditions and structures which open out the possibility of certain forms of interaction whilst closing others down (O'Neill, 2014). Through the critical engagement of those we were researching with, we were able to develop a space for shared thinking, retaining our epistemological commitments to narrative inquiry, whilst staging the interviews in ways that facilitated the interest and involvement of a group of vulnerable young men.

\section{Concluding messages}

In this paper I have revisited several pieces of research that I have conducted in the last 15 years, one in some detail. The second part of the paper's title ('journeys in knowing and not-knowing') communicates how the journey towards knowing involves an equivalent journey in the opposite direction. To return to Ingold, what we come to learn about-and through-our research practice is not 'governed by cognitive mechanisms of one sort or another, but an improvisatory movement - of 'going along' ... that is open-ended and knows no final destination' (Ingold, 2010: S122). This involves developing a capacity to learn to live with uncertainty, to relinquish elements of control and to attend to what unfolds.

The first qualitative research I describe in this paper demonstrates the problems of situating qualitative inquiry within an objectivist epistemological frame. The result, in this case, was the development of a highly stylised and problematic mode of qualitative inquiry (Silverman, 2007), in which we used our subject knowledge to elicit information from participants in the pursuit of pre-defined objectives. The BNIM study involved me shifting my research role towards a more passive mode in which I sought to create a space for a participant-led 'storytelling process' (Jones, 2003: 60). It was initially hard to adjust to this more passive interview approach, but with time and patience I was slowly able to become more observant and attentive to what unfolded. Epistemologically, adopting a narrative approach allowed me to maintain a central focus on my interviewee's individual biographies (the micro), whilst also working with these to explore the links to the systems that they lived and worked in (the meso), and wider social, political, economic and historical forces that they were subject to.

The most recent project I discuss, in which I used walking tour interviews, demonstrates the potential of newer approaches to narrative inquiry (O'Neill, 2014; Roy et al, 2015). This work suggests that whilst no single method is applicable in all cases, that principles from one approach can often be translated into different contexts in ways that are more relevant to securing the interest 
and involvement of those being studied. Throughout the paper, I have discussed the ways in which I have sought to consider and reconsider the epistemological consistencies and inconsistencies in my own practice and how, over time, I have sought to develop approaches which carefully consider how and what we might come to know through our research practice. As Polsky (1967/1998: 119) suggests 'Successful field research depends on the investigator's trained abilities to look at people, listen to them, think and feel with them...' I have learned that the modes and forms of inquiry we use are critical to productive knowledge making and that these modes and forms need to be altered-sometimes significantly-to make them applicable for different populations and contexts. 


\section{References}

Anderson, J. (2004) Talking whilst walking: a geographical archaeology of knowledge, Area 36(3), pp.254-261.

Back, L. (2000) The Art of Listening, London: Bloomsbury.

Back, L. and Duneier, M. (2006) 'Voices from the Sidewalk: Ethnography and Writing Race', in Ethnic and Racial Studies 29(3): 543-65.

Buckner, S. (2006) Taking the Debate on Reflexivity Further, in Journal of Social Work Practice, 19(1): 59-72.

Chase, S. E. (1995) 'Taking Narrative Seriously: Consequences for Method and Theory in Interview Studies', in R. Josselson and A. Lieblich (eds), The Narrative Study of Lives, Vol. 3. London: Sage. pp.1-26.

Duneier, M. and Back, L. (2006) Voices from the Sidewalk: Ethnography and Writing Race, in Ethnic and Racial Studies, 29:3, 543-565.

Fountain, J. Roy, A. Anitha, S. Davies, K. Bashford, J and Patel, K. (2007a) 'Issues Surrounding the Delivery of Prison Drug Services in England and Wales: With $A$ Focus On Black And Minority Ethnic Prisoners'. Preston: UCLan.

Froggett, L., and Wengraf, T. (2004) Interpreting Interviews in the Light of Research Team Dynamics: A Study of Nila's Biographic Narrative, Critical Psychology 10 pp.93-121.

Gunaratnam, Y. (2009) Narrative Interviews and Research, in Y. Gunaratnam and D. Oliviere, Narrative and Stories in Health Care: Illness, Dying and Bereavement. Oxford: Oxford University Press.

Gunaratnam, Y. (2013) Narrative Interviews - helping people to tell their stories, in Case Stories (http://www.case-stories.org/narrative-interviews-1/)

Hollway, W. (2001) The Psycho-Social Subject in 'Evidence-Based' Practice. Journal of Social Work Practice, 15(1): 9-22.

Hollway, W. and Jefferson, T. (2000/2012) Doing Qualitative Research Differently: Free Association, Narrative and Interview Method, London: Sage.

Hughes J, Roy A, Manley J (2014) Surviving in Manchester: Narratives on movement from the Men's rooms, Manchester. London: Lankelly Chase Foundation.

Ingold, T. (2011) Being Alive: Essays on Movement, Knowledge and Description. London: Routledge.

Jones. D. W. (2003) The Turn to Narrative Knowing of Persons: One Method Explored. Nursing Times Research, 8(1): 60-71. 
O'Neill, M. (2014) Participatory Biographies: Walking, Sensing and Belonging, in M. O'Neill, B. Roberts, and A. Sparkes, Advances in Biographical Methods: Creative Applications. London: Routledge.

Roy, A. (2012a) Rethinking Research on Drugs, Race and Ethnicity: A Psychosocial Approach. A thesis submitted in partial fulfilment for the requirements of a degree of PhD by Publication. Preston: University of Central Lancashire.

Roy, A. (2012b) The Life Narrative of a Mixed Race Man in Recovery from Addiction: A Case-Based Psycho-Social Approach to Researching Drugs, 'Race' and Ethnicity. The Journal of Social Work Practice, 27(4): 375-392.

Roy, A. Wibberley, C. and Lamb, J. (2005) The Usual Suspects: Alcohol, Tobacco and Other Drug Use in 15-16 Year Old School Pupils - Prevalence, Feelings and Perceived Health Risks, in Drugs: Education, Prevention and Policy, 12(4) pp. 305315.

Rustin, M. (1991) The Good Society and the Inner World: Psychoanalysis, Politics and Culture, London: Verso.

Scheff, T. J. (1997) Emotions, the Social Bond, and Human Reality: Part/Whole Analysis, Cambridge: Cambridge University Press.

Silverman, D. (2007) A Very Short, Fairly Interesting and Reasonably Cheap Book about Qualitative Research. London: Sage.

Wengraf, T. (2001) Qualitative Research Interviewing: Biographic Narrative and Semi-Structured Methods. London: Sage. 